\title{
Affecting and Satisfaction Factors for Practical Training of Skin Care related College Students
}

\author{
Moon-Joo Kim \\ Department of Beautician Art, Ansan University, Ansan-si, Gyeonggi-do, Korea
}

Corresponding author: Moon-Joo Kim, Department of Beautician Art, Ansan University, 155 Ansandaehak-ro, Sangrok-gu, Ansan-si, Gyeonggi-do 15328, Korea

Tel.: +82 314007041

Fax: +82 313637705

Email: mjkim@ansan.ac.kr

Received September 26, 2017

Revised January 22, 2018

Accepted February 19, 2018

Published June 30, 2018

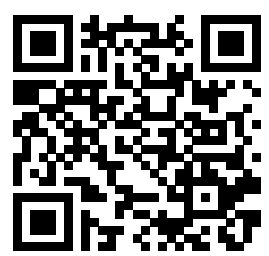

\begin{abstract}
Purpose: The purpose of this study was to investigate the affecting and satisfaction factors for practical training of skin care related college students. Methods: To accomplish this objective, a literature review and a questionnaire were conducted. Random sampling was conducted in September, 2016, in 32 universities. Out of 600 questionnaires, 496 were analyzed using Statistical Package for the Social Sciences (SPSS) 19.0, and frequency, reliability, factor, and multiple regression analyses were conducted. Cronbach's alpha was 0.772 to 0.817 . Results: First, $93.3 \%$ of the students responded that practical training was helpful in their major. For most of them, practical training was helpful in their local experience, career, and job hunt. Second, the most influential factors as regards practical training were diligence of the trainee. Third, the satisfaction factors regarding practical training were usefulness of practical training, prior preparation for work, prior preparation for university, and trainee aspect. Conclusion: It is necessary to formulate a plan to improve practical training by regulating the time spent on practical training and preparing the program in a manner that improves the trainee's diligence.
\end{abstract}

Keywords: Affecting factor, Satisfaction, Skin care, Student, Practical training

\section{Introduction}

\section{1. 연구의 필요성}

전문대학에 개설된 피부미용 관련학과에서는 2 학년 여름방학 을 활용하여 지난 3 학기 동안 학생들이 학습한 피부미용 교과목 의 이론과 실기 지식을 바탕으로 산업체에서 요구하는 인재육성 을 목표로 현장실습을 진행하고 있는 경우가 많다(Choi, 2017). 현장실습 교과목은 1997 년 법률 제 5316 호의 제정 및 공포를 통 해 정식 직업교육의 일환으로 인정받게 되었으며 관련 법령인 직업교육훈련촉진법에 의해서 산학협동 유형으로 분류되었다. 2010년 개정된 동 시행령에서는 학생들이 참여하는 실습의 총 기간을 고등교육법 제 20 조, 21 조의 규정에 의해 교육과정상의 교과과정 또는 수업 연한 학기의 범위 안에서 교육과학기술부 장 관이 정하는 특정 실습기간으로 규정하고 있다. 이러한 실습관련 법규에 따라 대학에서는 현장실습 교과목을 운영하고 있으며 학 생들은 학점이수, 취업 연계 및 현장경험 등의 이유로 현장실습 에 참여하고 있다(You \& Song, 2017). 피부미용 전공에서도 학
생들의 현장 적응력을 높이고, 학교에서 진행되는 교육과정과 실 제로 산업체에서 진행되는 고객 서비스간의 직무의 차이를 줄이 는데 도움이 되고자 시행되고 있는 현장실습 교과목은 중요한 교 육적 대안이 될 수 있다.

\section{2. 연구의 목적 및 의의}

대학 재학기간 중에 실시되고 있는 실습의 교육적 유용성에도 불구하고, 현장실습 교과목을 이수하는 학생 수가 지속적으로 줄 고 있고, 산업체와 대학에서도 현장실습 교과목의 활성화에 소극 적인 이유는 여러가지가 있다. 학생들 입장에서는 졸업 후의 진 로 선택에 대한 불확실성, 취업 분야가 확정되지 않은 점 등이 현 장실습 교과목 참여를 꺼리게 만들며 산업체 입장에서는 아직 피 부미용 능력이 부족한 학생들에게 현장실습 장소를 제공함에 대 한 부담감을 가지고 있고, 현장실습이 형식적으로 진행되는 경 우가 많아 학생들에게 실제적인 도움이 되지 않는다는 판단 등이 그 이유가 될 것이다. 또한, 실제로 실습생을 수용하는 대다수의 산업체에서 학생들을 위한 준비된 현장실습 프로그램이 매우 부 
족한 현실이고, 경우에 따라 학생들을 위한 별도의 사전교육 없 이 곧바로 학생들을 실무에 투입하는 사례도 있어, 현장실습을 통한 산업체 실무 교육이라는 취지와는 다르게, 산업체의 편의 에 따라 학생들을 임시 노동력으로 활용하는 경우가 많았다. 최 근 일과 학습 병행제, 국내외 인턴십 프로그램 등이 활성화 됨에 따라 국가, 사회, 대학, 산업체, 학생 모두 현장실습제도에 대하 여 강한 필요성을 느끼고 있으나(Jung \& Park, 2017) 실제적인 현장실습 운영 방법에 있어서 다양한 문제점이 표출되고 있다. 이에 본 연구에서는 그 동안 형식적으로 운영되고 평가되어 왔던 피부미용 현장실습 교과목에 대해서 수혜자인 학생들의 측면에 서 살펴볼 때 현장실습의 운영실태, 실습에 영향을 미치는 요인, 실습 만족도 요인을 점검해보고, 이를 통해 현장실습의 개선방안 을 마련함으로써 학생과 산업체 모두에게 도움이 될 수 있는 현 장실습의 효율적인 방안 마련을 위한 기초 자료 제공에 본 연구 의 의의가 있다.

\section{Methods}

\section{1. 연구대상 선정 및 자료수집 기간}

본 연구를 수행하기 위한 연구대상자는 지역별로 선정한 총 32 개 전문대학 피부미용 관련학과에 재학중인 2 학년 학생들로, 여름방학 기간 중 피부미용실에서 현장실습에 참여한 자로 선정 하였다. 자료수집 방법은 구조화된 설문지를 이용하여 학생들이 직접 자기기입식으로 작성한 후 수거하였다. 연구를 위한 조사기 간은 2016년 9월 5일부터 9월 30 일까지이며, 총 600 부의 설문 지를 배포하여 회수된 496 부가 분석에 사용되었다.

\section{2. 조사도구}

1) 일반적 특성 및 실습관련 요인

본 연구에서는 응답자의 일반적 특성으로 거주 지역, 거주지 단위, 주관적 경제상태 총 3 문항으로 구성되었고, 실습관련 요인 으로 $\operatorname{Kim}$ (2016), Kim \& Kim (2017), Park (2016)의 연구를 참조하여 실습의 타당성, 실습의 목적(복수 응답), 실습지 선택, 추후 실습참가 희망유무, 실습비 유무, 실습비 수준, 실습비의 적정성, 실습 기간, 실습 후 전공에 대한 느낌, 실습 후 산업체에 대한 느낌, 실습 후 진로 선택 등 총 11 개 문항으로 구성되었으 며, 측정방법은 명목척도를 사용하였다.

\section{2) 실습에 영향을 미치는 요인 및 만족도 요인}

본 연구에서는 피부미용을 전공하고자 하는 학생들이 실습을 통해 전공 관련 만족도를 높일 수 있는 효율적인 운영방안을 모 색하기 위해 실습에 영향을 미치는 요인 및 만족도 요인을 측정 하기 위한 문항을 선정하였다. 실습에 영향을 미치는 요인의 경
우, Enomoto (2017), Kamiya et al. (2016), Kim \& Chun (2016) 및 Song et al. (2016)의 연구를 참조하여 총 4개의 요 인으로 분류하였다. 4 개의 요인은 현장실습의 유용성, 산업체의 사전 준비, 대학의 사전 준비, 실습생 측면 등 요인으로 분류하 고, 각 요인별 세부 문항은 연구자가 연구 목적에 맞도록 일부 수 정하여 총 11 개 문항을 선정하였다. 그 내용으로는 실습의 유용 성(취업결정, 진로 결정, 실습능력 향상, 인맥형성), 산업체의 사 전 준비(실습 전 실습생을 위한 산업체 주관 사전교육, 실습생 교 육을 위한 산업체 준비, 산업체에서 실시한 사전교육에 대한 학 생들의 만족여부), 대학의 사전준비(실습에 참여한 산업체에 대 한 사전조사 및 학생들에게 내용 전달, 실습 교과목의 학점부여 관련 사항 전달, 산업체에서 실시하고 있는 전문지식 전달), 실 습생 측면(성실성)이다. 만족도 요인으로는 Lee (2016a)의 연구 를 참조하여 연구자가 연구 목적에 맞도록 일부 수정하여 산업체 프로그램 만족도, 직원의 실습 업무 지도, 적절한 지도 감독, 객 관적인 평가의 총 4 문항으로 선정되었다.

\section{3. 분석방법}

본 연구의 자료는 SPSS window 19.0 프로그램(IBM, USA) 을 사용하여 다음과 같은 방법으로 분석되었다. 연구 대상자의 일반적 특성 및 실습관련 문항은 명목 척도를 사용하였고, 실습 에 영향을 미치는 요인과 실습의 만족도 문항은 리커트 5 점 척도 를 사용하였다. 설문지의 구성은 Table 1 과 같다. 구체적인 분석 방법은 유효표본의 일반적 특성을 파악하기 위하여서는 빈도분 석, 각 설문항목의 신뢰성과 타당성 검증은 Cronbach's $\alpha$ 와 요 인분석, 실습 만족도에 미치는 인과관계를 검증하기 위하여서는 요인 값을 이용한 다중회귀분석을 이용하였다.

\section{Results}

\section{1. 일반적 특성 및 실습관련 요인}

\section{1) 일반적 특성}

응답자의 일반적 특성은 Table 2 와 같다. 거주지역으로는 경 기 지역(37.3\%)이 가장 많았으며, 거주지 단위로는 중소도시 (47.6\%)가 가장 많았다. 주관적 경제상태로는 '하'의 비중이 $58.7 \%$ 로 가장 많은 비중을 나타내었다.

2) 실습관련 요인

실습관련 요인을 살펴본 결과는 Table 3 과 같다. 실습의 타 당성 측면에서는 '보통이다' 이상의 응답자 비율이 $93.3 \%$ 로 나 타나 대부분의 학생들이 '실습은 필요한 것'으로 생각하고 있었 다. 실습의 목적을 살펴보기 위해 응답자들로 하여금 2 개의 복 수응답을 하게 하였는데, 각 문항에 대해서 가중치는 두지 않았 
Table 1. Composition of questionnaire

\begin{tabular}{llr}
\hline Variables & Measurement & Frequency \\
Demographic characteristics & Name measure & 3 \\
Practical training related questionnaire & Name measure & 11 \\
Affecting factors and satisfaction factors & 5-Likert measure & 15 \\
Total & & 29 \\
\hline
\end{tabular}

\section{Table 2. General characteristics}

\begin{tabular}{|c|c|c|}
\hline Provision & Variables & Frequency (\%) \\
\hline \multirow{5}{*}{ Residence area } & Seoul & $86 \quad(17.3)$ \\
\hline & Gyeonggi-do & $185(37.3)$ \\
\hline & Daejeon and Chungchung-do & $53(10.7)$ \\
\hline & Taegu and Gyeongsangbuk-do & $96(19.4)$ \\
\hline & Busan and Gyeongsangnam-do & 76 (15.3) \\
\hline \multirow{3}{*}{ Residence unit } & Big city & 158 (31.9) \\
\hline & Small and medium cities & $236(47.6)$ \\
\hline & Country & $102(20.6)$ \\
\hline \multirow{3}{*}{ Subjective economic status } & High & $23 \quad(4.6)$ \\
\hline & Middle & $182(36.7)$ \\
\hline & Low & $291(58.7)$ \\
\hline
\end{tabular}

다. 가장 중요하게 생각하는 실습의 목적은 '적성에 맞는 전공 선 택'(40.2\%), '취업 연계'(39.2\%)로 나타나 실습을 통해 학생들은 자신의 전공 선택에 도움을 받을 수 있으며 졸업 후 실습을 통한 취업연계까지 될 수 있기를 희망하고 있었다. 실습지는 '교수 소 개'(92.9\%)로 조사되어 실습과 관련해서 전공교수의 역량 및 노력 이 중요하다는 것을 알 수 있었다. 추후 '실습 참가 희망' 유무에서 '예'라고 대답한 비율이 $61.9 \%$ 로 실습 교과목에 대한 학생들의 선 호도는 비교적 높다고 볼 수 있다. 또한, '실습비를 지급 받는 경 우'가 $47.4 \%$ 를 나타났는데, '4주 기준 70 만원 이상' 실습비를 지 급받은 경우가 $46.0 \%$ 에 달하는 것으로 나타났다. 이는 최근 산업 체에서의 인력 수급 문제로 인해 산업체에서는 현장실습과 연계하 여 우수한 학생들을 추후 직원으로 채용하기를 희망하는 사례가 늘어나고 있고, 단지 방학 중 실시되는 교과목으로서의 현장실습 의 차원을 넘어 인턴 직원으로서 학생들을 대우하는 산업체가 늘 어남에 따라 산업체에서 실습비를 최저시급 기준에 준해서 학생 들에게 지급하고 있는 사례가 많았다. 그러나 산업체에 따라 실습 비가 없거나 30 만원 미만으로 지원하는 업체도 있어 학생들이 실 습비의 적정성의 경우 '부족', '매우 부족'이라고 생각하는 경우가 $26.8 \%$ 에 달하고 있다. 이와 같이 실습비 지급은 산업체의 규모, 직원 수에 비례하여 산업체에서 지급하는 실습비 수준의 차이가 매우 큰 것으로 생각되는데 이와 관련하여 대학에서 자체적으로
실습비 지원과 같은 재정적 뒷받침이 요구되어지고 있으며, 전적 으로 대학에서 실습비를 지급하기 어려운 경우 산업체와 대학 간 의 조율이 필요할 것으로 보인다. 따라서 학생들이 실질적으로 현 장실습에 관심을 갖고 참여율을 높이기 위해서는 현실적인 실습비 지급이 중요할 것으로 보인다. 실습 기간의 경우 '4주 이상'인 경 우가 $98.4 \%$ 이었으며, ' 8 주 이상'인 경우도 $25.2 \%$ 를 나타난 것으 로 미루어 현장실습이 산업체의 인턴십 개념으로 상당부분이 이루 어지고 있음을 알 수 있다. 현장실습 후 학생들의 전공에 대한 느 낌으로는 '보통' 이상이 $96.5 \%$ 로 나타나 실습 후 전공에 대해 긍 정적인 느낌을 갖는 것으로 나타났고, 실습 후 산업체에 대한 느 낌으로 '보통' 이상이 $96.8 \%$ 로 나타났다. 이는 현장실습 전공 및 현장실습 처를 선정할 때 학생들은 전공 교수와 심층 면담을 하였 고, 경우에 따라 산업체 면접을 보는 경우도 있어서 산업체에 대 한 대략적인 정보를 가지고 있는 경우가 많았다. 또한, 입학 후 현 장실습에 참여하기 전까지의 3 학기 과정을 통해 학생들은 자신의 전공분야가 확정된 상태로 현장실습에 임하는 경우가 많아 자신이 선택한 전공 및 산업체에 대해 호의적인 태도를 보이기 때문인 것 으로 생각된다. 또한 이러한 과정을 통해 실습 후 진로 선택에서 도 $91.3 \%$ 의 학생들이 피부미용 전공을 선택하고자 하는 것으로 나타났다. 
Table 3. Practical training factors

\begin{tabular}{|c|c|c|}
\hline Factor & Variables & Frequency (\%) \\
\hline \multirow{5}{*}{ Need for practical training } & Highly needed & $86 \quad(17.3)$ \\
\hline & Slightly needed & $192(38.7)$ \\
\hline & Not sure & 185 (37.3) \\
\hline & Rarely needed & $(5.0)$ \\
\hline & Not at all needed & (1.6) \\
\hline \multirow{4}{*}{ Purpose of practical training (two answers) } & Connections to obtain job & 389 (39.2) \\
\hline & Choice of major & 399 (40.2) \\
\hline & Work techniques/Job acquisition & 105 (10.6) \\
\hline & Obtaining credit & $99(10.0)$ \\
\hline \multirow{2}{*}{ Choice of practical training place } & Introduction from professor & 461 (92.9) \\
\hline & Found by student & $(7.1)$ \\
\hline \multirow{2}{*}{ Hope to undertake practical training (Yes/No) } & Yes & 307 (61.9) \\
\hline & No & $189(38.1)$ \\
\hline \multirow{2}{*}{ Practical training expenses (Yes/No) } & Yes & $235(47.4)$ \\
\hline & No & $261(52.6)$ \\
\hline \multirow{5}{*}{ Level of practical training expenses ( 4 weeks unit) } & Under 300 thousand & $(7.2)$ \\
\hline & 300 thousand-under 500 thousand & 39 (16.6) \\
\hline & 500 thousand-under 700 thousand & $71 \quad(30.2)$ \\
\hline & 700 thousand-under 900 thousand & $105(44.7)$ \\
\hline & Over 900 thousand & $(1.3)$ \\
\hline \multirow{5}{*}{ Appropriateness of practical training expense (4 week unit) } & Very appropriate & $34 \quad(14.5)$ \\
\hline & Appropriate & $89(37.9)$ \\
\hline & Neutral & $49 \quad(20.9)$ \\
\hline & Insufficient & $42(17.9)$ \\
\hline & Very insufficient & $(8.9)$ \\
\hline \multirow{4}{*}{ Period of practical training } & Under 2 weeks & $(0.0)$ \\
\hline & 2-4 weeks & (1.6) \\
\hline & $4-8$ weeks & $363(73.2)$ \\
\hline & Over 8 weeks & $125(25.2)$ \\
\hline \multirow{5}{*}{ Feeling about major after practical training } & Improved significantly & $84(16.9)$ \\
\hline & Improved & $243(49.0)$ \\
\hline & Neutral & $152(30.6)$ \\
\hline & Worsened & $10 \quad(2.0)$ \\
\hline & Worsened significantly & (1.4) \\
\hline \multirow{5}{*}{ Feeling about work after practical training } & Improved significantly & $87 \quad(17.5)$ \\
\hline & Improved & 238 (48.0) \\
\hline & Neutral & $155(31.3)$ \\
\hline & Worsened & $(1.8)$ \\
\hline & Worsened significantly & (1.4) \\
\hline \multirow{3}{*}{ Choice of career after practical training } & Skin care major & $453 \quad(91.3)$ \\
\hline & Beauty major (except skin care major) & (3.0) \\
\hline & Others (except beauty major) & $(5.6)$ \\
\hline
\end{tabular}




\section{2. 실습에 영향을 미치는 요인 및 만족도 요인}

1) 측정도구의 신뢰성 및 타당성 분석

(1) 실습에 영향을 미치는 요인의 신뢰성 및 타당성 분석

실습생의 실습에 영향을 미치는 요인을 도출하기 위해 Varimax 회전법을 통한 주성분 분석을 실시하였으며 신뢰성 분 석을 위해 각 요인별 신뢰도 계수(Cronbach's $\alpha$ )를 계산하였 다(Table 4), 실습에 영향을 미치는 요인의 신뢰성 및 타당성 분석결과 실습의 유용성(Cronbach's $\alpha=0.796)$, 산업체의 사 전 준비(Cronbach's $\alpha=0.817$ ), 대학의 사전 준비(Cronbach's $\alpha=0.772)$, 실습생 측면(Cronbach's $\alpha=0.782)$ 로 신뢰할 만한 수준에 있다고 볼 수 있다.
(2) 실습 만족도 요인의 신뢰성 및 타당성 분석

실습의 만족도를 나타내는 요인을 도출하기 위해 Varimax 회 전법을 통한 주성분 분석을 실시하였으며 신뢰성 분석을 위해 각 요인별 신뢰도 계수(Cronbach's $\alpha$ )를 계산하였다(Table 5). 실 습 만족도 요인의 변수로는 산업체 프로그램 만족도, 직원의 실 습 업무지도, 적절한 지도 감독, 객관적인 평가로 구성하였으며, Cronbach's $\alpha$ 값은 0.884 로 신뢰할 만한 수준에 있다고 볼 수 있다.

2) 실습 영향요인 분석

실습 영향요인 분석결과는 다음과 같다(Table 6). 응답자들은

Table 4. Reliability analysis and validity analysis on factors affecting practical training

\begin{tabular}{lccc}
\hline Variables & Eigen value & Degree of dispersion & Cronbach's $\alpha$ \\
Usefulness of practical training & 5.071 & 34.628 & 0.796 \\
Prior preparation for work & 3.086 & 24.036 & 0.817 \\
Prior preparation for university & 1.094 & 15.226 & 0.772 \\
Trainee aspect & 2.037 & 21.337 & 0.782 \\
\hline
\end{tabular}

$\mathrm{KMO}=0.776$; Bartlett gutter certification value $\mathrm{x}^{2}=1596.248$; Total cumulative $=71.064 \%$; KMO, Keiser-Meyer-Olkin .

Table 5. Reliability analysis and validity analysis on factors regarding satisfaction about practical training

\begin{tabular}{lccc}
\hline Variables & Eigen value & Degree of dispersion & Cronbach's $\alpha$ \\
$\begin{array}{l}\text { Satisfaction factors about practical } \\
\text { training }\end{array}$ & 2.904 & 15.223 & 0.884 \\
\hline
\end{tabular}

KMO=0.790; Bartlett gutter certification value $x^{2}=1490.936$; Total cumulative=69.049\%; KMO, Keiser-Meyer-Olkin.

Table 6. Factor analysis on practical training

\begin{tabular}{|c|c|c|c|c|c|}
\hline Factor & Variables & Mean & $\begin{array}{l}\text { Standard } \\
\text { deviation }\end{array}$ & $\begin{array}{l}\text { Ranking } \\
\text { in factor }\end{array}$ & $\begin{array}{l}\text { Ranking } \\
\text { in total }\end{array}$ \\
\hline \multirow{4}{*}{$\begin{array}{l}\text { Usefulness of practical } \\
\text { training }\end{array}$} & Decision regarding finding a job & 3.998 & 0.997 & 1 & 2 \\
\hline & Decision regarding career & 3.986 & 0.854 & 2 & 3 \\
\hline & Improvement in ability for practical training & 3.895 & 1.091 & 3 & 4 \\
\hline & Development of personal connections & 3.698 & 0.654 & 4 & 6 \\
\hline \multirow{3}{*}{$\begin{array}{l}\text { Prior preparation for } \\
\text { work }\end{array}$} & Prior education before practical training & 3.407 & 1.094 & 2 & 7 \\
\hline & Preparation for work and trainee education & 3.708 & 1.005 & 1 & 5 \\
\hline & Satisfaction about prior education regarding work & 3.215 & 1.069 & 3 & 8 \\
\hline \multirow{3}{*}{$\begin{array}{l}\text { Prior preparation for } \\
\text { university }\end{array}$} & Messages regarding prior research about industry & 3.094 & 1.089 & 1 & 9 \\
\hline & Messages regarding credits for practical training & 2.862 & 1.117 & 2 & 10 \\
\hline & $\begin{array}{l}\text { Messages regarding expert knowledge about how to get into the } \\
\text { workplace }\end{array}$ & 2.847 & 1.098 & 3 & 11 \\
\hline Trainee aspect & Diligence & 4.357 & 0.895 & 1 & 1 \\
\hline
\end{tabular}


Table 7. Correlation regarding satisfaction factors about practical training

\begin{tabular}{|c|c|c|c|c|c|}
\hline Variables & Factors affecting practical training & $\begin{array}{l}\text { Standardized } \\
\text { regression } \\
\text { coefficient }\end{array}$ & $\begin{array}{l}\text { Unstandardized } \\
\text { regression } \\
\text { coefficient }\end{array}$ & $t$ value & $p$ value \\
\hline \multirow{5}{*}{$\begin{array}{l}\text { Satisfaction factors } \\
\text { regarding practical } \\
\text { training }\end{array}$} & Constant & 3.394 & & $69.416^{* * *}$ & 0.000 \\
\hline & Usefulness of practical training & 0.894 & 0.849 & $23.336^{* * *}$ & 0.000 \\
\hline & Prior preparation for work & 0.257 & 0.364 & $7.601^{* * *}$ & 0.000 \\
\hline & Prior preparation for university & 0.199 & 0.337 & $4.069^{* * *}$ & 0.000 \\
\hline & Trainee aspect & 0.108 & 0.092 & $3.194^{* *}$ & 0.004 \\
\hline
\end{tabular}

${ }^{* *} p<0.01 ;{ }^{* * *} p<0.001 ; R^{2}$, coefficient of determination.

실습에 영향을 미치는 가장 중요한 요인으로 실습생 측면의 '성 실성'을 가장 높게 평가하고 있었다. 이는 학생 스스로 실습이 취 업 및 진로 결정에 영향을 미친다는 것을 인지하고 있으며 산업 체 및 대학에서 실제로 실습을 위한 사전 준비를 철저히 한다 할 지라도 실습생의 성실성이 담보되지 못한다면 실습이 성공적으 로 이루어질 수 없음을 깨닫고 있음을 보여준다. 이를 통해 대학 에서는 학생들의 실습에 참여함에 있어 학생 스스로 성실성을 높 일 수 있는 인성교육, 직업의식, 미래교육 등의 기초학습 교육과 기존의 pass/fail 평가로 이루어지고 있는 실습 교과목을 학점제 로 평가함으로써 제도적으로 성실성을 높일 수 있는 노력을 강구 하여야 함을 시사한다. 실습의 유용성 측면에서는 '취업결정', '진 로결정', '실습능력 향상'을 중요한 실습영향 요인으로 보았다. 산 업체의 사전 준비로는 '실습생 교육을 위한 산업체 준비', 대학의 사전 준비로는 '실습 산업체에 대한 사전 조사 전달'이 각각 높게 평가되었는데, 실습을 보다 효용성 있게 운영하기 위해서 산업체 와 대학 간의 유기적인 관계망 구축을 통해 실습생들의 눈높이에 맞는 실습 프로그램 개발이 필요함을 보여준다. 즉, 실습생들을 위해 대학 및 산업체의 유기적이고 실질적인 실습 프로그램 개발 및 적극적인 실천의지가 효율적인 현장실습을 이룰 수 있을 것이 다.

\section{3. 실습 만족도에 대한 실습 영향요인 다중회귀분석}

실습 만족도에 대한 다중회귀분석의 결과는 Table 7과 같다. 실습에서의 만족도와 상관관계가 있는 실습 영향요인을 분석한 결과 실습의 유용성 $(t=23.336, p<0.001)$, 산업체의 사전 준비 $(t=7.601, p\langle 0.001)$, 대학의 사전 준비 $(t=4.069, p<0.001)$, 실 습생 측면 $(t=3.194, p<0.01)$ 의 수준에서 모두 유의한 것으로 나 타났다. 즉, 실습 만족도를 높이기 위해서는 실습이 학생들의 취 업 결정, 진로 결정, 실습 능력 향상, 인맥 형성 등 다양한 요인 에서 긍정적인 결과를 나타낼 수 있도록 대학 및 산업체 간의 긴 밀한 협조를 통한 노력이 필요하다. 또한, 산업체 및 대학에서 실습생들이 실습의 목적, 학점 부여 관련, 전문지식 전달, 실습
을 위한 사전 준비 등과 같은 내용을 철저히 준비함으로써 학생 들이 실습의 목적 및 과정 등을 잘 이해하고 다양한 목적을 성취 할 수 있도록 배려해야 할 것으로 생각된다.

\section{Discussion}

피부미용 관련학과에서 실시되고 있는 여름방학 현장실습의 효율적인 방안을 모색하기 위하여 기존에 실습에 참여하였던 전 국 32 개 전문대학 피부미용 전공학생들을 대상으로 설문조사하 여 현재 진행되어지고 있는 피부미용 현장실습 관련 요인 분석, 실습에 영향을 미치는 요인에 대한 분석, 학생들의 실습에 대한 만족도 분석을 통해 피부미용 실습 교과목의 효율적 운영을 위한 기초 자료 제공을 위해 본 연구를 진행하였다.

연구결과는 다음과 같다. 첫째, 실습관련 요인 분석 결과, 실 습의 타당성 측면에서 $93.3 \%$ 에서 실습은 필요한 것으로 응답하 고 있어 대다수의 학생들은 실습에 대해 긍정적인 교육과정으 로 생각하고 있었다. 실습의 목적으로는 적성에 맞는 전공 선택 (40.2\%), 취업 연계(39.2\%)순으로 높게 나타나 학생들은 실습을 통해 진로 및 취업과 관련된 도움을 받고자 함을 알 수 있다. 실 습비의 경우 최근에 문제 되었던 무임금 도제교육이 노동 인권을 침해한다는 취지 하에 산업체에서 실습비를 지급하는 사례가 많 아졌다. 70 만원 이상 실습비를 지급하는 산업체가 $46.0 \%$ 에 이 르고 있어, 과거 등록금 마련을 위한 아르바이트를 위해 현장실 습을 포기하였던 학생들도 적정한 실습비를 지원받고 실습을 할 수 있게 된 점은 고무적이라 할 수 있다. 둘째, 실습에 영향을 미 치는 요인으로 4 가지를 선정하여 살펴본 결과 가장 크게 실습에 영향을 주는 요인으로는 실습생 측면으로 '성실성'으로 나타났다. 실습의 유용성 측면에서 '취업 결정'과 '진로 결정'에 영향을 미치 고 있으며, 산업체의 사전 준비 요인의 경우 '실습생 교육을 위한 산업체 준비', '실습 전 산업체 사전 교육'이 영향을 미치는 주된 변수로 나타났다. 또한, 대학의 사전 준비 요인에서는 '실습 산 
업체에 대한 사전 조사 전달', '학점 부여 관련 사항 전달' 변수가 주요하게 나타났다. 셋째, 실습 만족도에 대한 실습 영향 요인 분석 결과 실습의 유용성, 산업체의 사전 준비, 대학의 사전 준 비, 실습생 측면의 모든 영향 요인에서 유의한 결과를 보였다.

이상의 연구결과를 토대로 다음과 같은 점을 제안하고자 한다.

첫째, 학생들은 실습의 타당성을 긍정적으로 생각하고 있었 고, 실습의 목적 또한 분명하게 인식하고 있었다. 실습 후 전공 에 대한 느낌이나 실습 후 진로 선택도 분명하게 나타나고 있었 다. 이와 같이 실습을 통한 교육적 효과가 높고, 학생들의 실습 을 통한 취업, 진로에 대한 의지가 높아짐을 감안할 때 현재 대부 분의 대학에서 진행되고 있는 4 주의 실습기간을 조정할 필요가 있다. Bae \& Ahn (2016)는 2개월이나 그 이상의 실습기간을 경 험한 학생들이 그보다 짧은 기간 중에 실습을 마친 학생들의 경 우보다 대체로 실습만족도가 높게 나타난 점을 지적하였는데 실 습 기간이 2 개월 미만의 현재보다 장기간으로 될 경우 실습내용 의 전달 및 취업 관련 강한 모티브를 형성 할 수 있다고 하였다. 또한, You \& Song (2017)도 실습을 8주 이상 실시한 학생들이 4 주 이하의 실습을 한 학생들보다 실습에 대해 더 긍정적인 반응 을 하는 것으로 나타났음을 보여주고 있다. 이와 관련하여 Lee (2016b), Park (2016), Kim \& Kim (2017)도 동일한 연구결 과를 발표하였다. 최근 사회맞춤형, NCS 교과목 운영과 관련하 여 산업체에서 요구하는 능력 단위 요소들을 교육하기 위해서 실 습 기간을 늘릴 수 있도록 교육과정 개편이 필요할 것으로 보여 진다. 그러나 현재의 교육과정 상에서 현장실습 교과목을 늘리기 에는 다양한 면에서 어려움이 예상된다. 최근 교육인적자원부 지 침에 의거하여 학점 및 시수를 $1: 1$ 로 조정하고, 전문대학의 경우 졸업 이수 학점을 80 학점 미만으로 조정하는 추세에 의거해 볼 때 신규 현장실습 교과목 개설은 많은 어려움이 예상된다. 이에 중간고사를 기점으로 중간고사 이전에 정규 교과목을 운영하고, 중간고사 이후에 현장실습 교육을 병행하여 진행하는 새로운 교 육방법을 제안하고자 한다.

둘째, 실습시기와 관련하여 기존에 진행되던 2학년 1 학기를 마친 후에 진행되는 하계 현장실습의 고정된 개념에서 탈피하여 1 학년 2학기 이후 동계 방학기간을 활용하는 것에 대해 긍정적 인 검토가 필요할 것으로 생각된다. 이와 관련하여 Kim (2016) 은 전문대학의 경우에 1 학년 2학기 종료 후 동계 방학기간과 2 학년 1학기 종료 후 하계 방학, 그리고 2학년 2학기 중에 실시하 는 것이 타당함을 설명하고 있다. 즉, 1 회성에 해당되는 2 학년 1 학기 종료 후 하계 현장실습은 제한적이고, 전공관련 실습을 단 1 회 진행함에 따라 전공을 변경하고자 하는 학생들에게는 선택 의 기회가 없다. 이러한 이유로 1 학년 2학기를 마친 후 동계 현 장실습을 진행함으로써 전공 선택을 힘들어 하는 학생들에게 새 로운 기회를 제공할 수 있을 것이다. 또한, 2 학년 1학기 종료 후 하계 방학기간 중에 시행하는 실습은 전공 심화과정에서 쌓은 현
장 관련지식을 활용할 수 있고, 또한 실습생의 경우 2 학년 2학기 국내 인턴십 프로그램을 통한 취업과 연계가 가능하기 때문이다. 이와 관련하여 Kim \& Lee (2016), Kim (2016), Seong et al. (2016)도 비슷한 연구결과를 보여주고 있다.

셋째, 실습비의 현실화이다. 현실성 있는 실습비 지급과 관련 하여 Zhang et al. (2014), Lee (2016a), Hwang et al. (2016) 은 실습의 중요성과 학생들의 실습 참여도를 높이기 위한 방안으 로 실습비의 중요성을 지적하였다. 실제로 산업체의 규모에 비 례해서 실습비 지원이 이루어지고 있는 상황이다. 비교적 규모 가 작지만 알차게 현장실습을 운영하고 있는 산업체에서는 학생 들의 실습비 이유로 실습을 꺼리는 경우가 많다. 이에 학교 차원 에서의 실습비 지원을 검토할 필요성이 있다. Han (2016)도 높 은 실습비와 만족도 간에는 상관관계가 있음을 설명하면서 실습 비의 지원방안이 필요함을 언급하고 있다. Seong (2016)와 Kim $\& \operatorname{Kim}$ (2017)도 산학실습의 불만족 이유로 실습비를 들고 있 다. 최근 경제 상황의 악화로 방학기간을 이용하여 등록금을 마 련하고자 아르바이트를 필수로 하여야 하는 학생의 경우 실습과 함께 실습비를 지원 받는다면 학생들의 참여율을 높일 수 있을 것이다. 또한, 대학 차원에서 생각해 볼 때 최근 등록금 동결 등 으로 재정이 취약해져 가고 있음으로 대학에서 학생들의 실습비 를 전적으로 지원하는 것에는 어려움이 예상된다. 이에 대학과 산업체 간의 적절한 협의를 통해 학생들의 요구에 부응할 수 있 는 실습비 지원이 필요할 것으로 생각된다.

넷째, 실습생 차원의 성실성을 제고할 수 있는 프로그램 마 련이다. Kim \& Chun (2016), Kikuchi et al. (2015), Na \& Jang (2016) 및 Ma \& Cui (2015)는 실습생의 커리어 구축 요 인과 관련된 실습 프로그램을 통해 학생들의 실습 참여 의지를 높일 수 있다고 하였다. 본 연구에서 실습에 영향을 미치는 가장 중요한 요인으로 실습생의 성실성 요인으로 나타났으므로, 학생 들의 실습에 대한 의지, 성실성, 목표의식을 끌어 낼 수 있는 사 전 실습교육 프로그램 마련이 필요할 것으로 생각된다.

\section{Conclusion}

현재 대학의 피부미용 관련학과에서 2학년 1학기를 마친 후 여름 방학기간을 활용하여 현장실습이 진행되고 있는 경우가 대 부분이나, 대학 및 산업체에서 실습에 대한 중요성을 느끼고 있 지 못하거나 만족도가 낮고, 평가방식에서도 pass/fail 방식으 로 대부분의 대학에서 진행됨에 따라 산업체, 대학 및 학생 모두 에게서 형식적인 학점 운영방식으로 여겨지고 있어, 그 실효성 이 낮다. 그러나 최근 교육개념이 일-학습 병행제, NCS 교육운 영체제의 확산으로 인해 주문식 교육에 의한 요구도가 높게 나타 나고 있고, 실제로 현장실습의 교육적 가치가 중요하게 생각되고 
있다. 즉, 수혜자인 학생 측면에서 도움이 될 수 있는 효율적인 실습 교과목운영의 중요성이 높아지고 있다. 연구결과를 통해 학 생들의 경우 실습을 긍정적인 교육과정으로 생각하고 있으며 이 를 위해 현장실습을 준비하는 대학에서는 학생들의 개인별 특성 을 파악하여 적성에 맞는 전공선택, 여름방학 현장실습 후 조기 취업 또는 학기제 현장실습을 진행할 수 있는 취업연계가 될 수 있도록 사전면담 및 준비가 요구되어진다.

실습비 지급과 관련하여 최근 대학 등록금 동결 등으로 재정이 점차 열악해지는 대학의 현실을 고려할 때, 대학에서 실습비를 지급하는 것은 현실적으로 어려운 면이 있다. 따라서 산업체에 서도 학생들의 현장실습을 통해 도움을 받을 수 있는 프로그램을 대학과 산업체가 공동 개발하고 산업체에서는 학생들에게 적정 수준의 실습비를 지급할 필요가 있다. 또한, 성공적인 현장실습 을 위해서 가장 담보되어야 할 요인은 실습생의 성실성이므로 성 실성을 제고할 수 있는 평가 프로그램 개발 및 현장실습을 통한 전공 이해 및 취업 연계와 같은 정보 제공을 위한 사전 교육 프로 그램이 선행되어져야 할 것이다.

본 연구는 다음과 같은 한계점을 갖는다. 첫째, 표본의 대표 성 문제이다. 본 연구에서 표본으로 선정된 학생들은 실습에 대 한 강한 의지가 있어 현장실습 교과목을 스스로 선택한 경우 임 을 감안할 때 본 연구 결과를 일반화하기에는 다소 무리가 있다 고 생각된다. 또한, 최근 실습 교과목을 의무적으로 시행하지 않 고 있는 대학들이 많고, 전국 100 여개의 피부미용 관련학과 재 학생 수를 고려할 때 본 연구결과를 일반화하기에는 다소 무리가 있을 수 있다. 둘째, 실습에 영향을 미치는 요인과 실습관련 만 족도 요인은 매우 다양할 수 있으나, 여기에서는 15 개로 한정하 였다는 점이다. 그럼에도 불구하고 본 연구결과가 기존 선행 연 구결과와 동일한 결과이면서도 실습생의 만족도를 높이기 위해 실습의 유용성 측면, 산업체의 사전 준비, 대학의 사전 준비, 실 습생 측면에서 실습에 영향을 미치는 요인을 살펴보고 실습생들 의 만족도를 높일 수 있는 방안을 모색해 봄으로써 추후 실습 교 과목 운영 및 신규 실습관련 프로그램 개설 면에서 활용이 가능 할 것으로 사료된다.

\section{References}

Bae JH, Ahn JS. A study on experience of foreign students in their social work field practicum: focused on $\mathrm{H}$ university Chinese international students' experience of difficulties. Social Work Practice \& Research, 91: 39-72, 2016.

Choi SE. Career preparation behaviors and career considerations based on career attitude types of cosmetology major college students. Asian Journal of Beauty and Cosmetology,
15: 291-298, 2017.

Enomoto M. A discussion on the difficulties of practical training recording felt by students: with a focus on processes by which the difficulties are mitigated. Journal of Tokyo Kasei Gakuin University Humanities and social science, 57: 19-30, 2017.

Han $\mathrm{KH}$. A study on the developed educational models of fashion educational curriculum and field placement of the school based enterprise. Journal of the Korean Fashion \& Costume Design Association, 18: 47-62, 2016.

Hwang ET, Lee CW, Lew JY. A human resource staffing program of SMEs through cooperative education program. Asia Pacific Journal of Small Business, 38: 4985, 2016.

Jung EY, Park MY. Work experience and satisfaction among beauty graduates in foreign countries. Asian Journal of Beauty and Cosmetology, 15: 33-43, 2017.

Kamiya T, Hoshino N, Horie M, Hira D, Morita S, Sasaki $\mathrm{M}$, Terada T. Effects of the intervention of nutritional education for pharmacy students in hospital practical training. Japanese Journal of Pharmaceutical Health Care and Sciences, 42: 825-833, 2016.

Kikuchi C, Matsunaga T, Suzuki T. Effects of training students through a program simulating medication administration and patient instructions in pre-training for practical training. Yakugaku Zasshi, 135: 809-820, 2015.

Kim MJ, Lee HJ. The development of the field placement manual based on national competency standard (NCS): focusing on hair-beauty capacity. Journal of the Korean Society of Beauty and Arts, 17: 219-231, 2016.

Kim OJ. The development of the pre-educational program model supporting the kindergarten field practice of preservice early childhood teachers. Korean Journal of Early Childhood Education, 36: 235-260, 2016.

Kim SJ, Kim EJ. An exploratory study on the rights of students in their social work field practicum: in the aspect of the rights to learn and the rights to work. Korean Journal of Social Welfare, 69: 147-174, 2017.

Kim YK, Chun MA. The effects of the learning experiences at the social work field placement on social work selfefficacy. Korean Journal of Social Welfare Research, 50: 161-188, 2016.

Lee ES. A study on the perception differences between 
internship students and employees in exhibition and convention industry. International Journal of Trade Fairs and Exhibition Studies, 11: 35-49, 2016 a.

Lee JE. Analysis of educational needs for the development of a cognitive apprenticeship-based field education assistance tool: with a focus on learners at D university. The Journal of Learner-Centered Curriculum and Instruction, 16: 1075-1101, 2016b.

Ma Y, Cui D. College students' diversified practical skills training using innovative ideas: the example of botany teaching reform. Journal of Anhui Agricultural Science, 43: 347, 2015.

Na HB, Jang YJ. Study on major participants perception research for industrial design field placement system development. Journal of Digital Design, 16: 49-64, 2016.

Park YK. Effect of field placement among curriculum to career decision and job intention: focused on students of tourism related departments. Journal of Hotel \& Resort, 15: 593-610, 2016.
Seong E. An empirical study on the perception and experiences of field training for the students in tourism department. Journal of Mice \& Tourism Research, 44: 41-57, 2016.

Seong MG, Hwang SH, Kang HK, Jang KA. Influencing factors on satisfaction of clinical practice field in dental hygiene students. Journal of Korean Society of Dental Hygiene, 16: 391-399, 2016.

Song IH, Hwang IY, Lee NG. Influence of perception of hotel field practice education importance on satisfaction \& intention to find a job: targeting a participant in franchise hotel cooking file practice. Journal of Korea Entertainment Industry Association, 10: 179-187, 2016.

You JW, Song Y. Comparing latent means on job competencies, career resilience, career insight, and career identity of groups with and without field experience. The Journal of Career Education Research, 30: 181-200, 2017.

Zhang L, Su J, Chen L, Wang Y, Tang N. Practical ability training innovation for the full-time marine chemical engineering professional graduate students. Guangdong Chemical Industry, 41: 191-192, 2014. 


\section{국문초록}

\section{피부미용 관련학과 재학생의 산업체 실습에 영향을 미치는 요인 및 만족도}

김문주

안산대학교 뷰티아트과, 경기도 안산시, 한국

목적: 본 연구는 피부미용 관련학과 재학생의 산업체 실습에 영향을 미치는 요인 및 만족도 요인을 알아보기 위해 진행되었다. 방 법: 본 연구를 수행하기 위해 2016년 9월, 32개 전문대학 피부미용 관련학과에 재학중인 학생들로 여름방학 기간 중 피부미용실에 서 실습에 참여한 학생들을 대상으로 설문 조사하였다. 총 496 부가 분석에 사용되었다. 결과: 첫째, $93.3 \%$ 의 학생들이 현장실습은 도움이 되었다고 응답하였다. 대부분의 학생들이 현장실습은 현장경험에 도움이 되고, 진로 및 취업에 도움이 된다고 대답하였다. 두 번째, 가장 크게 실습에 영향을 주는 요인으로는 실습생 측면으로 '성실성'으로 나타났다. 셋째, 실습 만족도에 대한 영향요인 분 석결과, 실습의 유용성, 산업체의 사전 준비, 대학의 사전 준비, 실습생 측면이 영향요인으로 분석되었다. 결론: 현장실습의 기간 및 시기의 조정, 실습생의 성실성을 제고할 수 있는 프로그램 마련을 통해 현장실습의 효율성을 제고할 수 있는 방안 모색이 필요하 다고 사료된다.

핵심어: 영향요인, 만족도, 피부미용, 학생, 현장실습

\section{참고문헌}

김미정, 이현주. NCS기반 현장실습 매뉴얼 개발 연구. 한국인체미용예술학회지, 17: 219-231, 2016.

김수정, 김은정, 사회복지 현장실습 참여 대학생의 권리에 대한 탐색적 연구. 한국사회복지학, 69: 147-174, 2017. 김옥주. 예비유아교사의 학교현장실습을 지원하는 사전교육프로그램 모형 개발. 유아교육연구, 36: 235-260, 2016.

김유경, 전미애. 사회복지 현장실습에서의 학습경험이 실습에 대한 인식을 매개로 사회복지실천 효능감에 미치는 영향. 한 국사회복지조사연구, 50: 161-188, 2016.

나한범, 장영주. 산업디자인 현장실습 참여 주체별 인식도 조사를 통한 현장실습 시스템 개발 연구. 디지털디자인학연구,

16: 49-64, 2016.

박영기. 교육과정 중 현장실습이 진로결정과 취업의사에 미치는 영향: 관광관련학과 학생을 중심으로. 호텔리조트연구,

15: 593-610, 2016.

배진형, 안정선. 사회복지학전공 유학생의 현장실습 경험에 대한 연구: $\mathrm{H}$ 대학교 중국인 유학생의 어려움을 중심으로. 사 회복지실천과 연구, 91: 39-72, 2016.

성미경, 황세현, 강현경, 장경애. 치위생 전공 학생들의 현장실습기관 만족에 영향을 미치는 요인. 한국치위생학회지, 16 : 391-399, 2016.

성은희. 관광학부 학생들의 현장실습 인식 및 경험에 관한 실증적 연구. MICE관광연구, 44: 41-57, 2016.

송익회, 황일영, 이남겸. 호텔현장실습교육 참여의 중요도 인식이 현장실습 만족도와 취업의사에 미치는 영향. 한국엔터테 인먼트산업학회논문지, 10: 179-187, 2016.

유지원, 송윤희. 대학생의 현장실습교육 경험 유무 집단에 따른 실무역량, 진로탄력성, 진로통찰력, 진로정체성의 잠재평 균 비교. 진로교육연구, 30: 181-200, 2017.

이은성. 전시·컨벤션산업에서의 현장실습에 대한 실습생과 직원간의 인식차이에 관한 연구. 무역전시연구, $11: 35-49$, 2016a.

이정은. 현장실습의 인지적 도제 기반 지원도구 개발을 위한 교육요구도 분석: $\mathrm{D}$ 대학 학습자를 중심으로. 학습자중심교과 교육연구, 16: 1075-1101, 2016b. 
정은영, 박미영. 뷰티 전공자의 해외취업 실태 및 만족도에 미치는 영향. 아시안뷰티화장품학술지, 15: 33-43, 2017. 최승은. 2 년제 미용전공자들의 진로태도 유형에 따른 진로 준비행동과 취업 고려요인. 아시안뷰티화장품학술지, 15: 291298, 2017.

한경희. 패션 전공 교육과정과 학교기업 현장실습 연계 교육모델 개발 연구. 한국의상디자인학회지, 18: 47-62, 2016.

황의택, 이춘우, 류준열. 중소기업 인력채용 방안으로서의 장기현장실습의 국내외 운영사례의 시사점과 정책적 과제. 중소 기업연구, 38: 49-85, 2016. 


\section{中文摘要}

\section{皮肤美容相关学科在校学生的产业实习的影响因素和满意度}

金汶珠

安山大学美容艺术学科, 京畿道安山市, 韩国

目的: 本研究的目的是调查皮肤护理相关大学生实习的影响因素和满意度。方法: 为了进行本研究, 2016年9 月在32所专门大学皮肤美容相关学科在校学生进行问卷调查。共 496份用于分析。结果：首先，93.3\%的学生 回答说, 实习对他们的专业有帮助。对于他们中的大多数人来说, 实践培训有助于他们的现场经验, 职业和求 职。其次, 在实践培训方面影响最大的因素是实习生方面的“诚实”。第三, 关于实践培训的满意度结果显示, 实用培训, 产业的事先准备工作, 大学的事先准备和培训生方面为影响因素。结论: 有必要通过调整实践培训 时间和周期以及提高实习生诚实的方案来找到一种提高现场实习效率的方法。

关键词: 影响因素, 满意度, 皮肤美容, 学生, 现场实习 